\title{
The genetic structure of Escherichia coli populations in feral house mice
}

\author{
David M. Gordon \\ Tel: +616249 3552. Fax: +616249 5573. e-mail: David.Gordon@anu.edu.au
}

Division of Botany and Zoology, Australian National University, Canberra, ACT 0200, Australia

\begin{abstract}
Escherichia coli was isolated from feral house mice (Mus domesticus) during the course of a mouse plague in the state of Victoria, Australia. Two farms were sampled over a period of 7 months and a total of 447 isolates were collected. The isolates were characterized using the techniques of randomly amplified polymorphic DNA and multi-locus enzyme electrophoresis. The mean genetic diversity of this $E$. coli population $(H=0.24)$ was found to be substantially lower than the diversity of an $E$. coli population reported elsewhere for a single human host. Analysis of the allozyme data revealed that there were significant differences in the relative abundance of genotypes between the two localities sampled and among sample dates. Overall, however, spatial and temporal effects accounted for less than $5 \%$ of the genotypic diversity. Allele frequencies and the relative abundance of the more common genotypes did not differ between male and female hosts. The number of genotypes and genotype diversity increased as the age of the host increased, suggesting that the mice are continuing to acquire new $E$. coli clones throughout their life. The frequency of some alleles changed with respect to host age, which indicates that clone acquisition may not be a random process. It is argued that the low level of genetic diversity observed in this population of $E$. coli reflects the boom and bust nature of mouse population density in this region of Australia.
\end{abstract}

Keywords: Escherichia coli, allozymes, genotypic diversity, population genetics, mouse

\section{INTRODUCTION}

Studies concerning Escherichia coli have formed the empirical basis of our understanding of the genetic structure of bacterial populations (Milkman, 1973; Selander \& Levin, 1980; Whittam et al., 1983a, b; Miller \& Hartl, 1986; Maynard Smith et al., 1993; Guttman \& Dykuizen, 1994). Many of these studies have focused on clinical isolates responsible for a variety of diseases (Caugant et al., 1983; Selander et al., 1986b; Whittam et al., 1993). Some have examined issues related to clonal diversity and turnover in a single host (Caugant $e t$ al., 1981) or the degree to which strains are shared between hosts (Caugant et al., 1984). Virtually all of these studies have been restricted to $E$. coli isolated from humans. Notable exceptions to the observed bias towards human isolates do exist but they are few in number (Routman $e t$ al., 1985; Whittam, 1989). An additional major bias present in many previous studies has been their basis on

Abbreviations: ETs, electrophoretic types; MLEE, multi-locus enzyme electrophoresis; RAPD, randomly amplified polymorphic DNA. ad hoc collections of isolates of diverse geographic origin. Few studies have examined the structure of $E$. coli populations from a single host species or geographic locality.

The purpose of this study was to examine the genetic structure of E. coli from feral house mouse (Mus domesticus) populations and to investigate the role that host, spatial and temporal factors play in determining the structure of these populations. Collections were made in a region of Australia where house mouse population numbers regularly attain plague status, an event which occurred during this study. Over 440 strains of E. coli were isolated from two localities over a 7 month period and characterized using the techniques of randomly amplified polymorphic DNA (RAPD) and multi-locus enzyme electrophoresis (MLEE).

\section{METHODS}

Study site and host collection. Mice were collected from two wheat-growing properties (Stone and Symes) $15 \mathrm{~km}$ apart near the town of Walpeup in the Mallee district of north western 
Table 1. Details of mouse samples

\begin{tabular}{|llcc|}
\hline \multirow{2}{*}{ Sample criteria } & \multicolumn{2}{c|}{ Number of mice in sample } \\
\cline { 3 - 4 } & & Stone & Symes \\
\hline Date & Dec 1993 & 26 & 23 \\
& Jan 1994 & 42 & 37 \\
& Feb 1994 & 33 & 37 \\
& Mar 1994 & 32 & 30 \\
Host sex & Apr 1994 & 49 & 49 \\
Host age & Jun 1994 & 44 & 45 \\
& Male & 129 & 139 \\
& Female & 97 & 82 \\
& $<5$ weeks & 34 & 54 \\
& 5-8 weeks & 52 & 79 \\
& $>8$ weeks & 140 & 88 \\
\hline
\end{tabular}

Victoria, Australia. There are no discernible differences between the two study sites in terms of topography, vegetation, land use or the proximity to human habitation. Trapping transects were established in a single field on each property. At intervals throughout the summer and autumn of 1993/94, 100 live traps were placed along each transect in the evening and checked the following morning. Efforts were made to trap 50 mice per site on every sampling occasion. The required number of animals were usually captured in a single night.

A total of 447 mice were sampled. The numbers of hosts partitioned by sample site, date, sex and age are presented in Table 1. Males represent $60 \%$ of the mice collected, a bias resulting from the fact that males are more active and move over a greater area than females such that males are more susceptible to capture. The age structure of the host population varied between sites with adults accounting for $62 \%$ of the captures at the Stone site and $40 \%$ at Symes. The population at Symes started breeding approximately 1 month later than at Stone and this explains the greater proportion of young mice captured at Symes. Mouse population density peaked in April/May at both localities.

Isolation and characterization of bacteria. The hosts were killed and eviscerated at the field laboratory. The large intestine was opened aseptically and a sample of the upper colon contents was taken using a sterile swab. The swabs were placed in Aimes transport agar (Power \& McCuen, 1988) and stored at $5{ }^{\circ} \mathrm{C}$ until processed.

A single presumptive $E$. coli clone was isolated from every animal by streaking the swab onto a MacConkey agar plate (Power \& McCuen, 1988). Every isolate was subsequently purified by subculture onto another MacConkey agar plate followed by an LB agar plate (Power \& McCuen, 1988). All isolates were tested for growth on minimal lactose and minimal citrate agar plates (Power \& McCuen, 1988) and the $\mathrm{Lac}^{+} \mathrm{Cit}^{-}$isolates presumed to be $E$. coli. The isolates were then stored in glycerol at $-80^{\circ} \mathrm{C}$. Subsequently all isolates were subjected to further biochemical tests and found to exhibit characteristics typical of E. coli (Ewing, 1986; Power \& McCuen, 1988). All incubations were carried out at $37^{\circ} \mathrm{C}$.

Genotypic characterization of strains. Two 10-mer primers were used in the RAPD analysis: B01, 5' GTTTCGCTCC; and A19, 5' CAAACGTCGG (Operon Technologies). Tem- plate DNA was prepared by pelleting $1 \mathrm{ml}$ of an overnight $\mathrm{LB}$ culture and resuspending it in $50 \mu$ l sterile ultra-pure water. Cells were lysed by alternate 1 min cycles in boiling water and liquid nitrogen. The cellular debris was pelleted and $1 \mu$ of the supernatant used per reaction. Reaction volumes were $10 \mu \mathrm{l}$ and the reaction mix consisted of: $67 \mathrm{mM}$ Tris/ $\mathrm{HCl}, \mathrm{pH} 8.8$, $16.6 \mathrm{mM}\left(\mathrm{NH}_{4}\right)_{2} \mathrm{SO}_{4}, 1.5 \mathrm{mM} \mathrm{MgCl}_{2}, 0.2 \mathrm{mM}$ dNTPs, $0.45 \%$ Triton $\mathrm{X}-100,0 \cdot 2 \mathrm{mg}$ gelatin $\mathrm{ml}^{-1}, 3 \cdot 1 \mathrm{ng}$ primer $\mu \mathrm{l}^{-1}$. PCR amplification conditions were: 5 cycles of $92^{\circ} \mathrm{C}$ for $10 \mathrm{~s}, 40^{\circ} \mathrm{C}$ for $120 \mathrm{~s}$ and $72^{\circ} \mathrm{C}$ for $90 \mathrm{~s}$, then 35 cycles of $92^{\circ} \mathrm{C}$ for $5 \mathrm{~s}$, $45^{\circ} \mathrm{C}$ for $25 \mathrm{~s}$ and $72^{\circ} \mathrm{C}$ for $90 \mathrm{~s}$ and finally 1 cycle of $92^{\circ} \mathrm{C}$ for $10 \mathrm{~s}, 45^{\circ} \mathrm{C}$ for $20 \mathrm{~s}$ and $72{ }^{\circ} \mathrm{C}$ for $300 \mathrm{~s}$. The resulting PCR product was visualized on ethidium-bromide-stained $6 \%$ polyacrylamide gels. This procedure was repeated at least twice for each strain to confirm its genotype.

MLEE assays were run using Titan III cellulose acetate gels (Hebert \& Beaton, 1993). Protein extracts were prepared by growing the strains in $20 \mathrm{ml} \mathrm{LB}$ at $37^{\circ} \mathrm{C}$ overnight. The cells were pelleted and washed twice in $0.15 \mathrm{M}$ potassium phosphate buffer, $\mathrm{pH} 7 \cdot 0$, and then resuspended in $50 \mu \mathrm{l}$ lysis buffer $\left(1^{-1}\right.$ : $100 \mathrm{mg}$ NADP, $0.5 \mathrm{ml} \mathrm{2-mercaptoethanol).} \mathrm{The} \mathrm{cell}$ suspension was sonicated in three $5 \mathrm{~s}$ bursts while being kept chilled on ice. The sonicated suspension was centrifuged at $4^{\circ} \mathrm{C}$ and 13000 r.p.m. for $20 \mathrm{~min}$ and the supernatant was stored at $-80^{\circ} \mathrm{C}$. The following enzyme systems were used: $\mathrm{ADH}$ (alcohol dehydrogenase EC 1.1.1.1), AK (adenylate kinase EC 2.7.4.3), G6PD (glucose-6-phosphate dehydrogenase EC 1.1.1.49), $\mathrm{MDH}$ (malate dehydrogenase EC 1.1.1.37), MPI (mannose phosphate isomerase EC 5.3.1.8), MR (menadione reductase EC 1.6.99.2), 6PGD (6-phosphogluconate dehydrogenase EC 1.1.1.44), GPI (phosphoglucose isomerase EC 5.3.1.9), PGM (phosphoglucomutase EC 5.4.2.2), $\mathrm{SDH}$ (shikimate dehydrogenase $\mathrm{EC} 1.1 .1 .25$ ) and SOD (superoxide dismutase EC 1.15.1.1). MPI, GPI and PGM were run in $0.025 \mathrm{M}$ Tris/glycine buffer, $\mathrm{pH} 8.5$; all others were run in $0.1 \mathrm{M}$ Tris/maleate buffer, $\mathrm{pH} 7.8$ (Hebert $\&$ Beaton 1989). All strains were run at least twice to confirm their genotype.

Statistical analyses. The genetic distances between the strains were calculated as $D=1-\left[2 m_{\mathrm{xy}} /\left(m_{\mathrm{x}}+m_{\mathrm{y}}\right)\right]$ where $m_{\mathrm{xy}}$ is the number of RAPD bands (or alleles) shared by isolates $x$ and $y$, while $m_{\mathrm{x}}$ and $m_{\mathrm{y}}$ are the total number of bands (or alleles) present in isolates $x$ and $y$, respectively (Nei \& Li, 1979). RAPD and MLEE distance matrices were compared using the Mantel test (Rohlf, 1993). Phenograms were constructed from the distance matrices using the unweighted pair group method (UPGMA) (Rohlf, 1993). The reliability of the phenograms was determined by bootstrapping (Rohlf, 1993) as follows. Loci (MLEE) or bands (RAPD) were randomly selected, with replacement, to produce 50 replicated data sets of the same size as the original data sets. New distances matrices were then calculated and subjected to UPGMA analysis. Comparisons of the bootstrapped phenograms or RAPD and MLEE phenograms were made using the Strict Consensus method (Rohlf, 1993).

The total number of genotypes in the population was estimated by drawing 50 random samples of isolates of varying size $(S)$ with replacement and then determining the number of MLEE genotypes present in each random sample (Selander $e t$ al., 1987). The resulting data were then described by the following monotonic function: $\mathrm{ETs}=\alpha[1-\exp (-\beta S)]^{(1 / \delta)}$, where ETs denote the number of genotypes in a sample of size $S$. The parameters $\beta$ and $\delta$ determine the shape of the curve and $\alpha$ the asymptote, or the estimated total number of genotypes in the population. 
Genotypic diversity was estimated as $G=\left(1-\Sigma g_{\mathrm{i}}^{2}\right) n /(n-1)$ where $g$ is the frequency of genotype $i$ and $n$ is the total number of isolates. The proportion of genotypic diversity attributable to a particular effect (e.g. locality) is $\left(G_{\mathrm{T}}-G_{\mathrm{s}}\right) / G_{\mathrm{T}}$, where $G_{\mathrm{s}}$ is the arithmetic mean of $G$ calculated separately for each locality and $G_{\mathrm{T}}$ is the diversity of all isolates regardless of locality (Nei, 1978; Selander et al., 1986a).

The frequency of the $i$ th allele at the $j$ th locus is $p_{i j}$. The probability that two individuals differ at the $j$ th locus is $h_{\mathrm{j}}=$ $\left(1-\Sigma p_{\mathrm{ij}}^{2}\right) n /(n-1)$. The mean genetic diversity, $H$, is the arithmetic mean of $h_{\mathrm{j}}$ for $m$ loci (Nei, 1978; Selander et al., 1986a).

Estimates of multi-locus linkage disequilibrium were based on the index developed by Brown et al. (1980). $K$ is the total number of loci at which two individuals differ, there are $n(n-1) / 2$ such pairs in a sample of $n$ individuals. The mean difference between two individuals is $K=\Sigma h_{j}$. In the absence of linkage disequilibrium the expected variance of $K$ is $V_{\mathrm{e}}=$ $\Sigma h_{(}\left(1-b_{\mathrm{j}}\right)$. The observed variance of $K$ is $V_{0}$ and the index of linkage disequilibrium is $V_{0} / V_{e}$. To test if this ratio is significantly greater than one, a randomization test was employed. Samples of the same size as the original data set were generated by randomly sampling alleles, without replacement, according to their respective frequencies at each locus (Souza et al., 1993). For each random sample $V_{\mathrm{o}}$ and $V_{\mathrm{e}}$ are calculated and the probability of observing a $V_{o} / V_{\mathrm{e}}^{\circ}$ ratio as extreme as that for the original data is determined.

Analysis of deviance was used to compare genotype or allele frequencies with respect to locality, sample date, host age or sex. There is a bias inherent in the data as a result of the different age structure of the host populations at the two farms - a smaller proportion of adults at Symes. As a consequence, comparisons were adjusted for this bias where appropriate. Uncommon genotypes or rare alleles were not included in the analyses.

\section{RESULTS}

\section{RAPD versus MLEE results and clonal structure}

The two RAPD primers produced a total of 47 bands with a mean of six bands per strain. Among the 447 isolates there were 50 different RAPD genotypes. The 13 allozyme loci revealed a total of 43 alleles giving rise to 60 unique MLEE types. Pooling the RAPD and MLEE data resulted in a total of 88 genotypes.

Strains with identical RAPD types had different MLEE profiles while the converse was also true. Of the 50 RAPD types, $64 \%$ represented a single MLEE type, while one of the RAPD types encompassed as many as 10 MLEE types (Fig. 1). The corresponding MLEE comparison revealed that $80 \%$ of the MLEE types represented a single RAPD type. There were two MLEE types each of which was composed of six different RAPD types (Fig. 1).

The results of a UPGMA cluster analysis for the 88 genotypes based on the RAPD data and the MLEE results are presented in Fig. 1. Bootstrap analysis revealed that relatively little confidence can be placed on most of the nodes in either of the phenograms. The only consensus between the phenograms are the two clusters of strains indicated in Fig. 1. Cluster B consists of two genotypes, each with a unique RAPD and MLEE profile. Cluster A consists of 12 genotypes, consisting of five unique RAPD types and eight different MLEE types. The bootstrap analysis shows that these groups of strains consistently cluster in both UPGMA analyses (Fig. 1).

The degree of genetic similarity among the 88 genotypes implied by the RAPD and MLEE data are comparable. There was modest but significant correlation between the distance matrices derived from the two sets of data $(R=0.48, P<0 \cdot 001)$. Further support for the conclusion that both data sets imply similar genetic distances between the strains is given by the following analysis. On average, the 88 genotypes differed at four MLEE loci. There were significantly fewer differences (2.5) between different MLEE types with the same RAPD profile (median test, $P<0.001$ ).

An analysis of multi-locus linkage disequilibrium based on the MLEE data and considering the 88 genotypes revealed a significant degree of linkage disequilibrium $\left(V_{\mathrm{o}} / V_{\mathrm{e}}=1.76, P<0.001\right)$. When the analysis was restricted to the 12 genotypes forming cluster A no linkage disequilibrium could be detected $\left(V_{\mathrm{o}} / V_{\mathrm{e}}=0.98, P>\right.$ $0 \cdot 45)$. Similarly, when the analysis included all of the genotypes not present in clusters $\mathrm{A}$ or $\mathrm{B}(N=74)$, there was little evidence for linkage disequilibrium $\left(V_{\mathrm{o}} / V_{\mathrm{e}}=\right.$ $1 \cdot 21, P>0 \cdot 03)$.

\section{Genotypic diversity: temporal, spatial and host effects}

The following analyses have been based on only the allozyme data for three reasons. Firstly, most previous studies concerning the genetic structure of bacterial populations are based on MLEE data. Secondly, basing the analysis on the 88 genotypes resulting from pooling the RAPD and MLEE data results in a significant reduction in the number of times a particular genotype occurs in the sample. Finally, essentially the same outcomes are observed when the analyses are based on the RAPD data or the pooled RAPD and MLEE data.

Of the 60 MLEE types (ETs), 58\% were isolated only once while the three most common genotypes represented $48 \%$ of the isolates. Repeated random sampling of the isolates produced an estimated number of ETs of $\alpha=55 \pm 2.3$ (Fig. 2). As 60 ETs were identified, this suggests that all of the common ETs occurring in house mice at the two localities were recovered.

There were 46 ETs recovered from the Stone site and 34 from the Symes locality. Of the 25 ETs recovered more than once, $20 \%$ were present at only one of the sites: one absent from Stone and four absent from Symes. Considering only the 10 most abundant ETs, representing $75 \%$ of the 447 isolates, there was a significant difference in their frequency of occurrence between sites $\left(\chi^{2}=55.9, P<0.001\right)$.

Although there were significant differences in the relative abundance of the 10 most common ETs across sample 

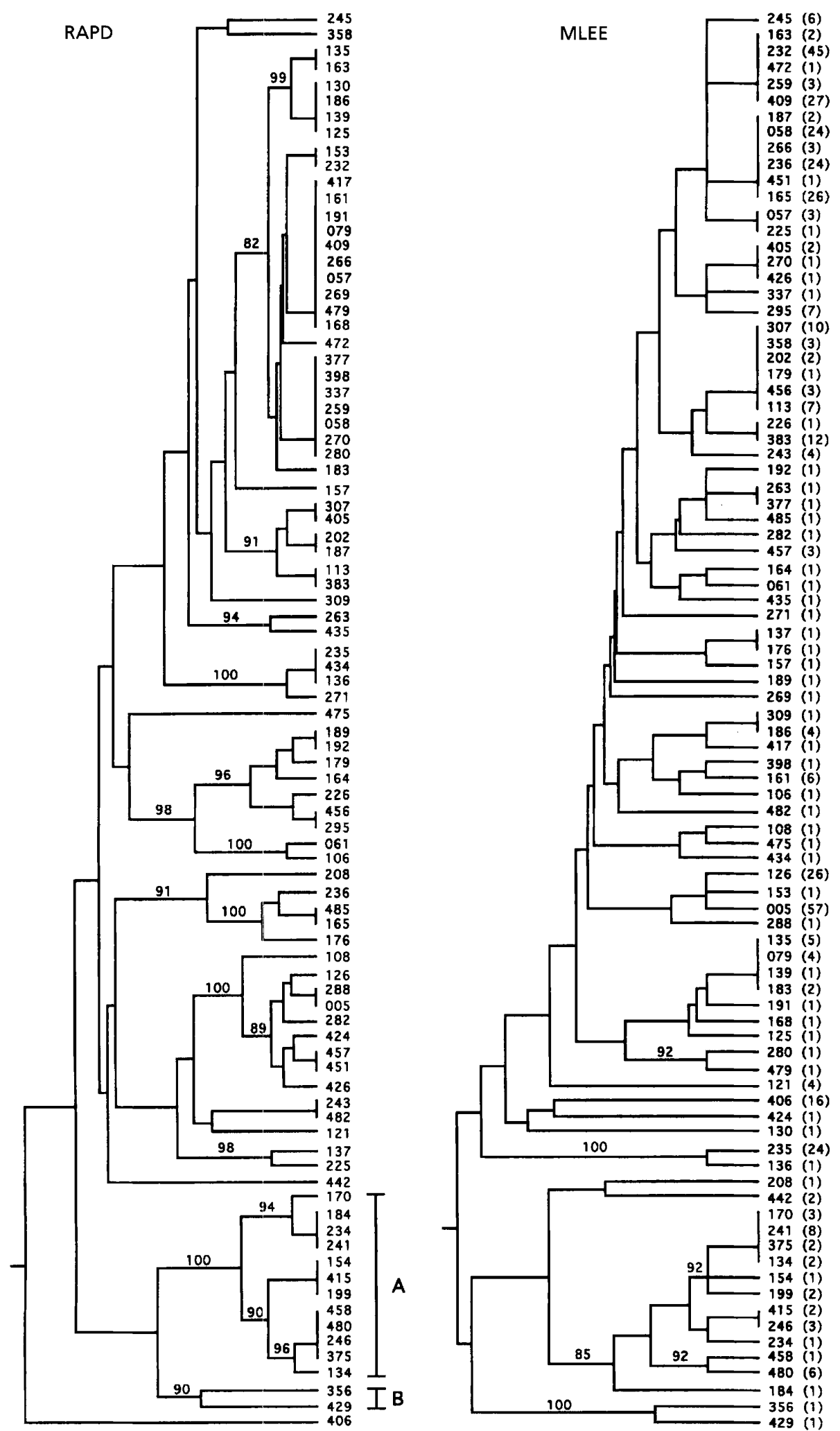

Fig. 1. Phenograms depicting the genetic similarities among $E$. coli strains isolated from feral house mice. In the phenogram based on RAPD data, strains connected by a vertical line represent strains with identical RAPD profiles but different MLEE profiles. The converse is true for the phenogram based on MLEE data. The numbers represent the isolate used as an example of the genotype (combined RAPD and MLEE results) and the bracketed figures present the number of times each of the genotypes were recovered. The vertical lines labelled A or B encompass those strains which clustered together in both the RAPD and MLEE phenograms. The phenograms were constructed using the UPGMA method. The bootstrap values for nodes are presented for only those clusters of strains which occurred more than $80 \%$ of the time. 


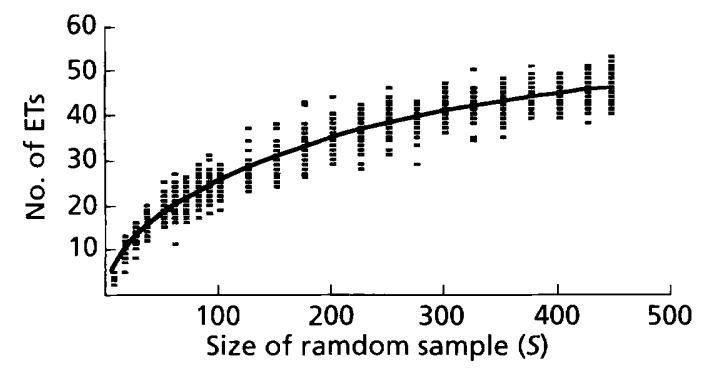

Fig. 2. Estimating the number of $E$. coli MLEE genotypes in the house mouse population. The symbols represent the number of genotypes that were present in random samples of size $S$ and the solid line depicts the fit of the empirical model. See Results for further details.

Table 2. Changes with host age in the genotypic diversity of $E$. coli isolated from house mice

\begin{tabular}{|lcc|}
\hline Host age & Richness* $^{*}$ & Evenness \\
\hline Juvenile & 25 & $10 \cdot 8$ \\
Sub-adult & 30 & $11 \cdot 7$ \\
Adult & 44 & $13 \cdot 5$ \\
\hline
\end{tabular}

* The number of genotypes (ETs) recovered from each host group.

†Simpson's Index $=\Sigma\left(n_{\mathrm{i}}\left(n_{\mathrm{i}}-1\right)\right) /(\mathrm{N}(\mathrm{N}-1))$ where $n_{\mathrm{i}}$ is the number of isolates of the $i$ th ET and $N$ is the total number of isolates.

dates $\left(\chi^{2}=92.49, P<0.001\right)$ no consistent trends could be observed. Some genotypes were recovered on every sampling occasion, some intermittently, and others were only observed in the early samples or the later samples.

No differences between the sexes could be detected in the relative frequency of the 10 most common ETs $\left(\chi^{2}=\right.$ $11 \cdot 77, P>0 \cdot 22)$. There were, however, significant differences in the relative frequencies of the 10 most common clones among the different ages of host $\left(\chi^{2}=\right.$ $35 \cdot 6, P<0 \cdot 008)$. Much of the age effect appears to be due to an increase in genotypic diversity with increasing host age. The number of genotypes recovered from each age class (richness) and the relative frequencies of the genotypes (evenness) increased as hosts aged (Table 2).

The total genotypic diversity, $G_{\mathrm{T}}$ - the probability of two randomly selected clones being different - was $0 \cdot 91$. Although there were significant differences in the relative abundances of the 60 ETs due to spatial, temporal and host effects, individually these factors did not account for any more than $5 \%$ of the total genotypic diversity.

\section{Allelic diversity: temporal, spatial and host effects}

There was an average of 3.3 alleles per locus. The allelic diversity at each locus is presented in Table 3 . The mean allelic diversity across all loci was $H=0 \cdot 24$ (isolates)
Table 3. Results of the allozyme analysis of $447 \mathrm{E}$. coli strains isolated from feral house mice

\begin{tabular}{|lccc|}
\hline Locus & No. of alleles & $\boldsymbol{h}_{\mathrm{i}}^{*}$ isolates & $\boldsymbol{h}_{\mathrm{i}} \dagger$ ETs \\
\hline ADH & 4 & 0.434 & 0.517 \\
AK & 3 & 0.428 & 0.380 \\
G6PD & 2 & 0.013 & $0 \cdot 095$ \\
MDH & 2 & 0.009 & 0.064 \\
MPI & 4 & 0.547 & 0.661 \\
MR1 & 3 & 0.272 & 0.445 \\
MR2 & 3 & 0.077 & 0.209 \\
MR4 & 2 & 0.009 & 0.064 \\
6PGD & 4 & 0.336 & 0.576 \\
GPI & 6 & 0.526 & 0.632 \\
PGM & 2 & 0.031 & 0.095 \\
SDH & 5 & 0.336 & 0.463 \\
SOD & 3 & 0.135 & 0.127 \\
Mean & $\mathbf{3 . 3}$ & $\mathbf{0 . 2 4}$ & $\mathbf{0 . 3 3}$ \\
\hline
\end{tabular}

*Genetic diversity calculated using all 447 isolates.

† Genetic diversity based on the 60 MLEE genotypes.

and $H=0.33$ (ETs). Significant differences between localities in the frequencies of one or more alleles were detected for the following loci; $\operatorname{ADH}\left(\chi^{2}=10 \cdot 3, P<\right.$ $0 \cdot 006)$, AK $\left(\chi^{2}=17 \cdot 1, P<0 \cdot 001\right)$, MPI $\left(\chi^{2}=22 \cdot 7, P<\right.$ $0.001)$ and 6PGD $\left(\chi^{2}=10 \cdot 4, P<0.01\right)$. Of the 43 alleles present, $16 \%$ were absent from one of the localities, six absent from Symes and one from Stone. Significant differences in allele frequencies among sample dates were detected for AK $\left(\chi^{2}=19 \cdot 2, P<0 \cdot 04\right)$, MPI $\left(\chi^{2}=\right.$ $20.5, P<0.03)$ and GPI $\left(\chi^{2}=22.4, P<0.02\right)$. No trends in the frequency of any allele through time could be observed. No differences in allele frequencies as a function of host sex were detected at any locus. Allele frequencies varied with respect to the age of the host for SDH and MPI (Table 4). As the age of the host increased the frequency of allele 4 declined while the frequency of allele 1 increased for MPI $\left(\chi^{2}=13.1, P<0.02\right)$. Allele 5 for SDH declined as host age increased $\left(\chi^{2}=10 \cdot 2, P<\right.$ 0.04).

\section{DISCUSSION}

The genetic diversity of this population of E. coli inhabiting house mice is 0.24 . By comparison, the diversity of the $E$. coli isolates taken from a single human host over a period of 11 months was found to be 0.47 (Caugant et al., 1981). Typically, genetic diversity estimates of $E$. coli isolated from human faecal flora range from 0.45 to 0.54 (Selander et al., 1987).

It is likely that numerous factors are responsible for the low level of genetic diversity in E. coli of house mice at these localities. It is thought that the natural life cycle of E. coli consists of transitions between two distinct habitats (Savageau, 1983). The lower intestine of its animal hosts represents its primary habitat while the environment external to the host (soil, water) represents 
Table 4. Changes in allele frequencies among $E$. coli isolated from hosts of different ages

\begin{tabular}{|ccccc|}
\hline \multirow{2}{*}{ Locus } & Allele & \multicolumn{3}{c|}{ Allele frequency $(\%)$} \\
\cline { 3 - 5 } & & Juveniles $(\boldsymbol{n}=\mathbf{8 8})$ & Sub-adults $(\boldsymbol{n}=\mathbf{1 2 8})$ & Adults $(\boldsymbol{n}=\mathbf{2 2 6})$ \\
\hline \multirow{2}{*}{ MPI } & 1 & 11 & 15 & 26 \\
& 3 & 17 & 18 & 17 \\
SDH & 72 & 67 & 57 \\
& 1 & 0 & 2 & 7 \\
& 2 & 2 & 52 & 87 \\
& 4 & 95 & 11 & 8 \\
\hline
\end{tabular}

its secondary habitat. Much of the diversity in the clonal composition of human E. coli populations is thought to be due to the continuous acquisition and extinction of clones. Clones are acquired through the ingestion of bacteria from the secondary habitat (primarily contaminated food) and are lost as a result of chance extinction and competition among clones within the host (Caugant et al., 1981; Whittam, 1989). In the region where this study was undertaken, human population densities are low and sewage treatment is of a high standard. The mammal community of the region is depauperate, consisting of very few native or domestic species and during plague years mice are certainly the most abundant mammal species in the region. Thus, most inputs to populations in the secondary habitat may be due to mice. Mouse population densities fluctuate dramatically, such that densities at the peak of a plague and densities during the inter-plague low can differ by 2-4 orders of magnitude (Berry \& Bronson, 1992). The same environmental conditions that inhibit mouse population growth between plagues (low rainfall and high temperatures) will probably also reduce the survival of the E. coli population in the secondary environment. Thus during inter-plague periods, which typically are of 3-4 years duration (Singleton \& Redhead, 1990; Berry \& Bronson, 1992), the lack of primary habitat (low host density) and poor survival in the secondary habitat may result in high rates of clone extinction, thereby significantly reducing diversity. In addition, when conditions favourable to a plague do occur mouse population numbers quickly increase (Singleton, 1989). At this time there may be intense selection for clones with the ability to rapidly colonize the primary habitat and this may further reduce genetic diversity. Clonal diversity of the E. coli population inhabiting the gut increases with host age, suggesting that mice continue to acquire clones throughout their life. That the acquisition of these clones is not a random process is suggested by the observation that allele frequencies for MPI and SDH differ among strains isolated from hosts of different ages (Table 4).

Significant differences in allele frequencies were detected among the six sample dates. However, the differences were only marginally significant $(0.01<P<0.05)$ and no systematic temporal trend in the frequency of any allele could be detected. Over the course of the study there were obvious seasonal changes in the environment and significant changes in the density of the mouse populations. However, it is not possible to determine whether these changes caused the temporal shifts in allele frequencies or whether these differences simply reflect sampling artefacts. In the study of an $E$. coli population from a sewage outflow, Pupo \& Richardson (1995) found significant fluctuations in the frequency of several alleles with time. Although they could not explain this, they concluded that the fluctuations were not due to sampling artefacts or temporal variation in the temperature or $\mathrm{pH}$ of the sewage outflow.

The RAPD and MLEE analyses gave broadly comparable results in describing the genetic similarity of the strains, producing similar UPGMA phenograms and a significant correlation between the distance matrices. Furthermore, strains with identical RAPD types differed at fewer MLEE loci than would be expected by chance. In an analysis of the strains in the $E$. coli reference collection (ECOR; Ochman \& Selander, 1984) a similar correspondence between RAPD and MLEE results was also found (Desjardins et al., 1995). Here we observed that $80 \%$ of the MLEE types represented a single RAPD type while only $64 \%$ of the RAPD types represented a single MLEE type, and this is primarily a consequence of the lower resolving power of the RAPD analysis. The two primers identified fewer (50) unique genotypes than the 13 loci examined in the MLEE analysis (60). RAPD analysis has been shown to be more capable of discriminating isolates than MLEE analysis in some circumstances (Wang et al., 1993). However, the sensitivity of the RAPD method will depend on the choice and number of primers used in the analysis. In this study, the RAPD primers were not selected for their ability to differentiate between isolates with identical MLEE profiles.

Analysis of the 88 genotypes identified on the basis of the combined RAPD and MLEE results revealed a highly significant level of linkage disequilibrium. Little evidence of linkage disequilibrium could be detected when the genotypes were partitioned on the basis of the UPGMA analysis. Gordon et al. (1995) discussed the problems associated with estimating linkage dis- 
equilibrium in subsets of strains identified on the basis of cluster analysis of MLEE data. In essence, the problem relates to using the same data to first identify strain clusters and then to estimate the amount of linkage disequilibrium among strains within clusters. It is not always possible to determine if the lack of linkage disequilibrium within subgroups of strains reflects recombination or the limitations inherent in the multilocus linkage disequilibrium index. The ability of the index to detect disequilibrium tends to decline as $H$ declines, and lower values of diversity are an inevitable consequence of selecting subsets of strains identified using cluster analysis. This bias can never be completely eliminated. Although the RAPD data provide 'independent' evidence for the clustering patterns observed using the MLEE data, the inherent statistical problems associated with analysing strain clusters remain.

Caugant et al. (1981) described a method for detecting recombination among strains within a population. Their method looked at those pairs of strains which differed at a single allozyme locus together with the plasmid profiles of those strains. If the strain pairs had very different plasmid profiles they considered this as evidence that the strains diverged prior to establishing in the host population. If the pairs had similar or identical profiles and one strain of the pair had a unique allele, they concluded that the difference between the strains arose due to mutation at that locus. However, if the plasmid profiles were similar or identical and the allele was present in other strains in the population, they considered this as evidence for recombination. Analysis of plasmid profiles in this population of $E$. coli (unpublished data) suggests that recombination can only be invoked as an explanation for $<5 \%$ of those strain pairs differing at a single locus. The evidence seems to suggest that the apparent absence of linkage disequilibrium within the subgroups of strains may be due to the limitations of the statistic $V_{\mathrm{o}} / V_{\mathrm{e}}$ rather than significant recombination.

There have been numerous studies concerning the genetic structure of E. coli populations and tests for multi-locus linkage equilibrium in these populations have consistently revealed significant levels of linkage disequilibrium. The one exception, has been the sewage outflow population of E. coli studied by Pupo \& Richardson (1995). Although they did observe linkage disequilibrium for some pairwise loci comparisons, when their data are analysed using a multi-locus estimate no linkage disequilibrium can be detected $\left(V_{0} / V_{\mathrm{e}}=\right.$ 0.98 , based on ETs). In a study of E. coli isolated from chickens and from the environment in which the birds were living, Whittam (1989) found that only $10 \%$ of the more than 100 clones identified were recovered from both habitats. The extent to which clones recovered from sewage outflows represent clones from the primary habitat (humans) or from the secondary habitat (waste traps, wall populations of sewage pipes, etc.) is not known. If sewage outflows are dominated by clones from the secondary habitat it is possible that not only does the clonal composition of primary and secondary habitats differ but that there are also real differences in the genetic structure of populations from the two habitats.

Genotypes were not distributed randomly among the two localities. The differences between localities may be a consequence of house mouse population dynamics. As the mouse population density peaks in a plague year, movements in search of food and increased levels of intra-specific aggression lead to marked increases in the rate at which mice disperse (Berry \& Bronson, 1992). High levels of dispersal could be expected to minimize differences in the clonal composition of E. coli populations between localities. However, during inter-plague periods when mouse population size is low the home range of breeding pairs is quite small and little dispersal occurs (Krebs et al., 1994). In addition, the spatial distribution of the mice becomes far more patchy during the inter-plague periods as mice are restricted to small areas of favourable habitat (Singleton, 1989). As previously suggested, clone extinction rates may be quite high between plagues. Low dispersal rates may fail to homogenize the differences arising between localities as a result of clone extinction. Furthermore, these extinction events may not be entirely random. The composition of the E. coli population at Symes did not so much represent a 'different' population from the one at Stone as it represented a subset of the Stone population. Overall, fewer genotypes were recovered from Symes and two of the more common genotypes were rare at Symes. Similar patterns were observed for alleles - of the 43 alleles observed, six were absent from Symes while only one was absent from Stone.

This study of E. coli in house mice also suggests that there are important interactions occurring between the dynamics of E. coli populations in their primary and secondary habitats. Further studies concerning the composition and transmission dynamics of E. coli in and between primary and secondary habitats would be valuable.

\section{ACKNOWLEDGEMENTS}

This study could not have been undertaken without the assistance of Grant Singleton and other members of the Rodent Control group of the Division of Wildlife and Ecology, Commonwealth Science and Industry Research Organization. The technical assistance of Arianne Lowe, Frances FitzGibbon and Leonie Moyle was invaluable. This study was funded by the Australian Research Council.

\section{REFERENCES}

Berry, R. J. \& Bronson, F. H. (1992). Life history and bioeconomy of the house mouse. Biol Rev 67, 519-550.

Brown, A. D. H., Feldman, M. W. \& Nevo, E. (1980). Multilocus structure of natural populations of Hordeum spontaneum. Genetics 96, 523-536.

Caugant, D. A., Levin, B. R. \& Selander, R. K. (1981). Genetic diversity and temporal variation in the $E$. coli populations of a human host. Genetics $98,467-490$. 
Caugant, D. A., Levin, B. R., Lidin-Janson, G., Whittam, T. S. Svanborg Eden, C. \& Selander, R. K. (1983). Genetic diversity and relationships among strains of Escherichia coli in the intestine and those causing urinary tract infections. Prog Allergy 33, 203-227.

Caugant, D. A., Levin, B. R. \& Selander, R. K. (1984). Distribution of multilocus genotypes of Escherichia coli within and between host families. J Hyg 92, 377-384.

Desjardins, P., Picard, B., Kaltenböck, B., Elion, J. \& Denamur, E. (1995). Sex in Escherichia coli does not disrupt the clonal structure of the population: evidence from randomly amplified polymorphic DNA and restriction-fragment-length polymorphism. $J$ Mol Evol 41, 440-448.

Ewing, W. H. (1986). Edwards and Ewing's Identification of Enterobacteriaceae, 4th edn. New York: Elsevier.

Gordon, D. M., Wexler, M., Reardon, T. B. \& Murphy, P. J. (1995). The genetic structure of Rhizobium populations. Soil Biol Biochem 27, 491-499.

Guttman, D. S. \& Dykuizen, D. E. (1994). Clonal divergence in Escherichia coli as a result of recombination, not mutation. Science 266, 1380-1383.

Hebert, P. D. N. \& Beaton, M. J. (1989). Methodologies for Allozyme Analysis Using Cellulose Acetate Electrophoresis. Beaumont, TX: Helena Laboratories.

Krebs, C. J., Singleton, G. R. \& Kenny, A. J. (1994). Six reasons why feral house mouse populations might have low recapture rates. Wildl Res 21, 559-567.

Maynard Smith, J., Smith, N. H., O'Rourke, M. \& Spratt, B. G. (1993). How clonal are bacteria? Proc Natl Acad Sci USA 90, $4384-4388$.

Milkman, R. (1973). Electrophoretic variation in Escherichia coli from natural sources. Science 182, 1024-1026.

Miller, R. D. \& Hartl, D. L. (1986). Biotyping confirms a nearly clonal population structure in Escherichia coli. Evolution 40, $1-12$.

Nei, M. (1978). Estimation of average heterozygosity and genetic distance from a small number of individuals. Genetics 89, 583-590.

Nei, M. \& Li, W.-H. (1979). Mathematical model for studying genetic variation in terms of restriction endonucleases. Proc Natl Acad Sci USA 76, 5269-5273.

Ochman, H. \& Selander, R. K. (1984). Standard reference strains of Escherichia coli from natural populations. I Bacteriol 157, 690-693.

Power, D. A. \& McCuen, P. L. (1988). Manual of BBL Products and Laboratory Procedures, 6th edn. Cockeysville, MD: Becton Dickinson Microbial Systems.

Pupo, G. M. \& Richardson, B. J. (1995). Biochemical genetics of a natural population of Escherichia coli: seasonal changes in alleles and haplotypes. Microbiology 141, 1037-1044.

Rohlf, F. J. (1993). Numerical taxomomy and multivariate analysis system, version 1.80. New York: Exeter Software.

Routman, E., Miller, R. D., Philips-Conroy, J. \& Hartl, D. L. (1985).
Antibiotic resistance and population structure in Escherichia coli from free-ranging African yellow baboons. Appl Environ Microbiol 50, 749-754.

Savageau, M. A. (1983). Escherichia coli habitats, cell types, and molecular mechanisms of gene control. Am Nat 122, 732-744.

Selander, R. K. \& Levin, B. R. (1980). Genetic diversity and structure in Escherichia coli. Science 210, 545-547.

Selander, R. K., Caugant, D. A., Ochman, H., Muser, J. M. \& Whittam, T. S. (1986a). Methods of multilocus enzyme electrophoresis for bacterial population genetics and systematics. Appl Environ Microbiol 51, 873-884.

Selander, R. K., Korhonen, T. K., Vaisanen-Rhen, V., Williams, P. H., Pattison, P. E. \& Caugant, D. A. (1986b). Genetic relationships and clonal structure of strains of Escherichia coli causing neonatal septicaemia and meningitis. Infect Immun 52, 213-222.

Selander, R. K., Caugant, D. A. \& Whittam, T. S. (1987). Genetic structure and variation in natural populations of Escherichia coli. In Escherichia coli and Salmonella typhimurium, Cellular and Molecular Biology, pp. 1625-1648. Edited by F. C. Neidhardt, J. L. Ingraham, K. Brooks Low, B. Magasanik, M. Schaechter \& H. E. Umbarger. Washington, DC: American Society for Microbiology.

Singleton, G. R. (1989). Population dynamics of an outbreak of house mice (Mus domesticus) in the mallee wheatlands of Australia - hypothesis of plague formation. J Zool (Lond) 219, 495-515.

Singleton, G. R. \& Redhead, T. D. (1990). Structure and biology of house mouse populations that plague irregularly: an evolutionary perspective. Biol J Linn Soc 41, 285-300.

Souza, V., Nguyen, T. T., Hudson, R. R., Piñero, D. \& Lenski, R. E. (1993). Hierarchical analysis of linkage disequilibrium in $R h i-$ zobium populations: evidence for sex? Proc Natl Acad Sci USA 89, 8389-8393.

Whittam, T. S. (1989). Clonal dynamics of Escherichia coli in its natural habitat. Antonie Leeuwenhoek 55, 23-32.

Whittam, T. S., Ochman, H. \& Selander, R. K. (1983a). Geographic components of linkage disequilibrium in natural populations of Escherichia coli. Mol Biol Evol 1, 67-83.

Whittam, T. S., Ochman, H. \& Selander, R. K. (1983b). Multilocus genetic structure in natural populations of Escherichia coli. Proc Natl Acad Sci USA 80, 1751-1755.

Whittam, T. S., Wolfe, M. L., Wachsmuth, I. K., Ørskov, F., Ørskov, I. \& Wilson, R. A. (1993). Clonal relationships among Escherichia coli strains that cause hemorrhagic colitis and infantile diarrhoea. Infect Immun 61, 1619-1629.

Wang, G., Whittam, T. S., Berg, C. M. \& Berg, D. E. (1993). RAPD (arbitrary primer) PCR is more sensitive than multilocus enzyme electrophoresis for distinguishing related bacteria strains. Nucleic Acids Res 21, 5930-5933.

Received 2 September 1996; revised 24 January 1997; accepted 7 February 1997. 